\title{
Rosmarinic Acid Increases Macrophage Cholesterol Efflux through Regulation of ABCA1 and ABCG1 in Different Mechanisms
}

\author{
Jean-Baptiste Nyandwi ${ }^{1,2,3}{ }^{(D)}$, Young Shin Ko ${ }^{1}$, Hana Jin ${ }^{1}$, Seung Pil Yun ${ }^{1}$, Sang Won Park ${ }^{1,2}$ \\ and Hye Jung Kim $1,2, *$ (D)
}

1 Department of Pharmacology, Institute of Health Sciences, College of Medicine, Gyeongsang National University, Jinju 52727, Korea; nbaptiste1988@gmail.com (J.-B.N.); shini33@naver.com (Y.S.K.); hanajin.kr@daum.net (H.J.); spyun@gnu.ac.kr (S.P.Y.); parksw@gnu.ac.kr (S.W.P.)

2 Department of Convergence Medical Science (BK21 Plus), Gyeongsang National University, Jinju 52727, Korea

3 Department of Pharmacy, School of Medicine and Pharmacy, College of Medicine and Health Sciences, University of Rwanda, Kigali 4285, Rwanda

* Correspondence: hyejungkim@gnu.ac.kr

Citation: Nyandwi, J.-B.; Ko, Y.S.; Jin, H.; Yun, S.P.; Park, S.W.; Kim, H.J. Rosmarinic Acid Increases Macrophage Cholesterol Efflux through Regulation of ABCA1 and ABCG1 in Different Mechanisms. Int J. Mol. Sci. 2021, 22, 8791. https:// doi.org/10.3390/ijms22168791

Academic Editor: Anna Solini

Received: 14 June 2021

Accepted: 13 August 2021

Published: 16 August 2021

Publisher's Note: MDPI stays neutral with regard to jurisdictional claims in published maps and institutional affiliations.

Copyright: (c) 2021 by the authors. Licensee MDPI, Basel, Switzerland. This article is an open access article distributed under the terms and conditions of the Creative Commons Attribution (CC BY) license (https:// creativecommons.org/licenses/by/ $4.0 /)$

\begin{abstract}
Lipid dysregulation in diabetes mellitus escalates endothelial dysfunction, the initial event in the development and progression of diabetic atherosclerosis. In addition, lipid-laden macrophage accumulation in the arterial wall plays a significant role in the pathology of diabetes-associated atherosclerosis. Therefore, inhibition of endothelial dysfunction and enhancement of macrophage cholesterol efflux is the important antiatherogenic mechanism. Rosmarinic acid (RA) possesses beneficial properties, including its anti-inflammatory, antioxidant, antidiabetic and cardioprotective effects. We previously reported that RA effectively inhibits diabetic endothelial dysfunction by inhibiting inflammasome activation in endothelial cells. However, its effect on cholesterol efflux remains unknown. Therefore, in this study, we aimed to assess the effect of RA on cholesterol efflux and its underlying mechanisms in macrophages. RA effectively reduced oxLDL-induced cholesterol contents under high glucose (HG) conditions in macrophages. RA enhanced ATP-binding cassette transporter A1 (ABCA1) and G1 (ABCG1) expression, promoting macrophage cholesterol efflux. Mechanistically, RA differentially regulated ABCA1 expression through JAK2/STAT3, JNK and PKC-p38 and ABCG1 expression through JAK2/STAT3, JNK and PKC-ERK1/2/p38 in macrophages. Moreover, RA primarily stabilized ABCA1 rather than ABCG1 protein levels by impairing protein degradation. These findings suggest RA as a candidate therapeutic to prevent atherosclerotic cardiovascular disease complications related to diabetes by regulating cholesterol efflux in macrophages.
\end{abstract}

Keywords: ABCA1; ABCG1; cholesterol efflux; diabetic atherosclerosis; macrophages; rosmarinic acid

\section{Introduction}

Atherosclerosis is the key driver of vascular diseases such as stroke, angina, myocardial infarction and brain ischemia in diabetes and obesity [1,2]. Lipid dysregulation in diabetes mellitus escalates endothelial inflammation and dysfunction, critical events involved in atherogenesis [3,4]. Monocytes are primordial inflammatory cells in early atherosclerotic plaques that have been reported to play an integral role in atherosclerosis progression [5]. Monocytes interact with endothelial cells (ECs), after which monocytes migrate in the subendothelial area of the vessel wall and differentiate into macrophages, where they take up cholesterol from retained lipoproteins and transform into foam cells, which play a critical role in the progression of atherosclerosis [6,7]. Macrophage lipid homeostasis depends on cholesterol engulfment and free cholesterol efflux, which are mediated by multiple molecules [8]. Overexpression of the scavenger receptors (SRs) such as cluster of differentiation (CD) 36 or lectin-like receptor for oxidized low-density lipoproteins (LOX-1) on macrophages triggers dysregulated cholesterol uptake, leading 
to foam cell formation in the subendothelial area [9]. Conversely, macrophage foam cell formation is inhibited by cholesterol efflux from macrophages and following metabolism by the liver $[10,11]$.

Macrophage cholesterol efflux and reverse cholesterol transport (RCT) substantially protect against the progression of atherosclerosis [12,13]. ATP-binding cassette transporter A1 (ABCA1) and G1 (ABCG1) mediate cholesterol efflux from foam cells to the extracellular cholesterol acceptors apolipoprotein A-I (ApoA-I) and high-density lipoprotein (HDL), respectively, thereby limiting foam cell formation and decreasing the progression of atherosclerosis $[14,15]$. Previous studies demonstrated that atherosclerosis-prone LDL receptor-deficient mice that were transplanted with bone marrow from ABCA1and ABCG1-knockout mice showed accelerated atherosclerotic lesion development [16], whereas mice that were transplanted with bone marrow from ABCA1-overexpressing mice exhibited decreased atherosclerosis progression [17]. Consistently, ablation of macrophage ABCA1 and ABCG1 in mice resulted in a substantial increase in atherosclerosis progression [18]. In addition, transgenic mice overexpressing ABCA1 showed a low incidence of atherosclerosis [19]. Moreover, studies in humans have reported that cholesterol efflux capacity is negatively correlated with atherosclerotic cardiovascular events [20-22]. Such evidence sheds light on the imperative roles of endothelial dysfunction, foam cell formation and cholesterol efflux in atherogenesis. Regarding the ABCA1 and ABCG1 induction mechanisms, liver $X$ receptor (LXR) agonists are the most well-identified transcription factors to stimulate ABCG1 and ABCA1 expression, resulting in promotion of cholesterol efflux from macrophages, and eventually protection against atherosclerosis in mice $[15,23]$. Moreover, it has been known that Janus kinase (JAK) activated signal transducer and activator of transcription 3 (STAT3) signaling pathway increased ABCA1 and ABCG1 levels in macrophages [24,25].

Rosmarinic acid (RA) is a natural phenolic ingredient found in Rosmarinus officinalis and other common culinary herbs from the Lamiaceae family [26]. Many studies have asserted that RA possesses antioxidant, anti-inflammatory, antidiabetic and cardioprotective activities $[27,28]$. We previously demonstrated that RA inhibits diabetic endothelial dysfunction by inhibiting inflammasome activation in ECs through downregulating the p38-FOXO1-TXNIP pathway [29]. However, the effect of RA on cholesterol efflux by macrophage remains unknown. Therefore, in this study, we aimed to investigate the atheroprotective effect of RA through enhancing cholesterol efflux and reducing cholesterol levels in macrophage. In particular, we have revealed the molecular mechanism associated with RA-mediated ABCA1 and ABCG1 induction.

\section{Results}

2.1. RA Reduced oxLDL-Induced Lipid and Cholesterol Contents under High Glucose (HG) Conditions in Macrophage

Under HG conditions, macrophages in the subendothelial area engulf oxLDL and transform into lipid-leaden macrophages or foam cells, which accelerate the inflammatory process and plaque formation during atherogenesis [30]. Hence, we examined whether RA could reduce lipid contents and cholesterol levels in macrophages treated with oxLDL under high glucose conditions. When we evaluated the effect of RA on macrophage viability, RA was not toxic to macrophages at $100 \mu \mathrm{M}$ for up to $72 \mathrm{~h}$ (Figure 1A,B). When THP-1 macrophages were stimulated with oxLDL under low glucose conditions, oxLDL treatment increased lipid accumulation, which was more enhanced in high glucose conditions (Figure 1C). HG- and oxLDL-induced lipid contents in THP-1 macrophages were reduced in the presence of RA (Figure 1C). We further examined the effect of RA on the cholesterol content of THP-1 macrophages. Fractionation analysis of the intracellular cholesterol profile demonstrated that RA dose-dependently decreased the intracellular total cholesterol content (Figure 1D), free cholesterol content (Figure 1E) and cholesteryl ester content (Figure 1F) in THP-1 macrophages treated with oxLDL under HG conditions. Because lipid uptake by macrophages is induced by SRs expressed on macrophages, we evaluated the effect of RA on the key SRs responsible for oxLDL uptake by macrophages, LOX-1 and CD36. 
RA treatment decreased LOX-1 and CD36 (Figure 1G,H) expression, which was increased by oxLDL under HG conditions, in a dose-dependent manner. These data demonstrate that RA effectively reduced lipid contents and macrophage foam cell formation by decreasing lipid uptake, which were enhanced by oxLDL under HG conditions.

A

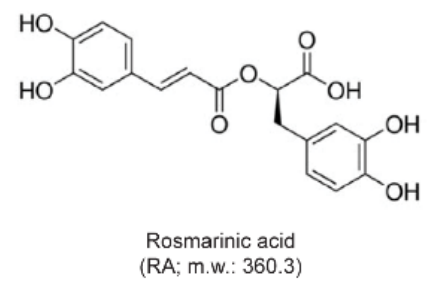

C

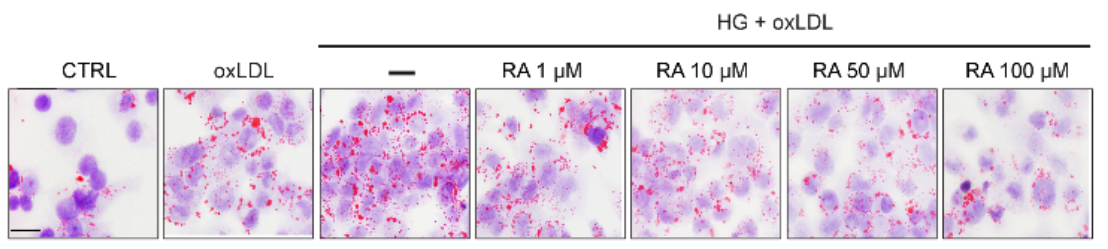

D

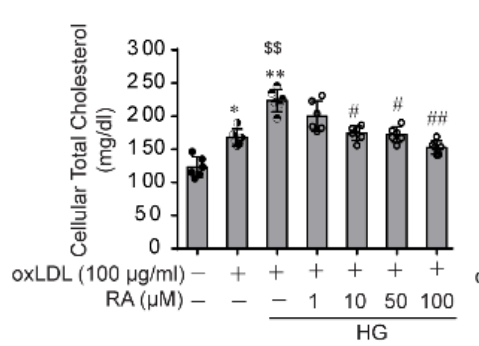

$\mathbf{G}$
B

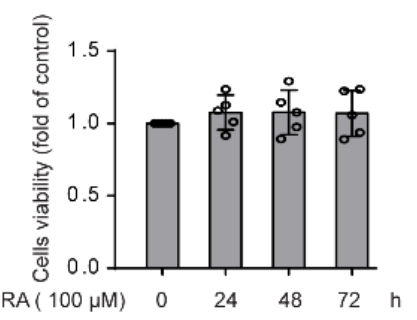

E
$\mathbf{F}$

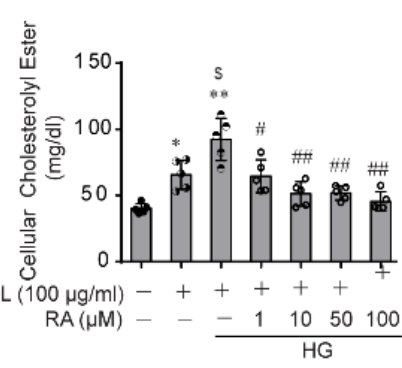

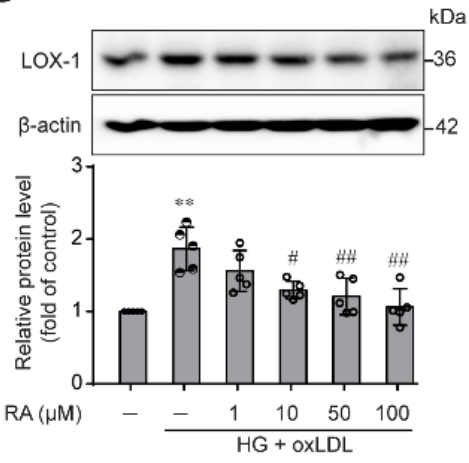

H

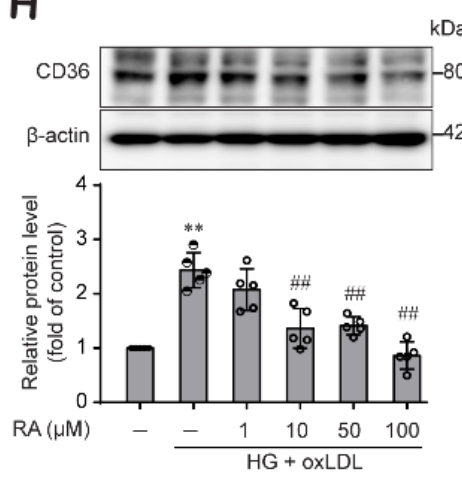

Figure 1. RA significantly reduced the oxLDL-induced lipid contents, cholesterol contents and levels of the SRs LOX-1 and CD36 in macrophage under HG conditions. (A) Chemical structure of RA. (B) Effect of RA on THP-1 macrophage viability. THP-1 macrophages were treated with RA $(100 \mu \mathrm{M})$ for 24,48 and $72 \mathrm{~h}$, and then cell viability was measured by the CCK-8 assay as described in the Methods section. Results are presented as the mean \pm SD from five independent experiments. (C) THP-1 macrophages were treated with oxLDL $(100 \mu \mathrm{g} / \mathrm{mL})$ under low glucose $(5 \mathrm{mM})$ or HG $(25 \mathrm{mM})$ conditions in the presence or absence of RA $(1,10,50$ and $100 \mu \mathrm{M})$. After $24 \mathrm{~h}$, intracellular lipids were stained with Oil Red O (ORO) and observed under light microscopy $(400 \times$ magnification) (scale bar: $50 \mu \mathrm{m})$. Results were confirmed by repeated experiments. (D-F) Cells were treated as described above, and intracellular total cholesterol (D), free cholesterol (E) and cholesteryl ester (F) were measured with a cholesterol/cholesteryl ester quantitation kit according to the manufacturer's instructions as described in the Methods section. LOX-1 (G) and CD36 (H) protein levels were analyzed from the cell lysates by western blot analysis. The data are presented as the mean $\pm \mathrm{SD}$ of five independent experiments. ${ }^{*} p<0.05,{ }^{* *} p<0.01$ compared to the control; $\$ p<0.05, \$ \$ p<0.01$ compared to the oxLDL; ${ }^{\$} p<0.05$, ${ }^{\# \#} p<0.01$ compared to the HG + oxLDL group. 


\section{2. $R A$ Increases Cholesterol Efflux by Upregulating $A B C A 1$ and $A B C G 1$}

Research findings suggested that $A B C A 1$ and ABCG1 are key transporters that facilitate cholesterol egress from macrophages, reducing atherosclerosis development [14]. We then explored the effect of RA on the protein expression levels of ABCA1 and ABCG1 in THP-1 macrophages stimulated with oxLDL under HG conditions. oxLDL treatment did not affect $\mathrm{ABCA} 1$ or $\mathrm{ABCG} 1$ protein expression levels in THP-1 macrophages maintained under HG conditions. Interestingly, RA treatment dose-dependently increased ABCA1 (Figure 2A) and ABCG1 (Figure 2B) protein levels in THP-1 macrophages. Then, we assessed whether the RA-mediated increases in the ABCA1 and ABCG1 proteins impacted cholesterol efflux efficiency in THP-1 macrophages. RA significantly increased cholesterol efflux to the extracellular cholesterol acceptors ApoA1 (Figure 2C) and HDL (Figure 2D) in THP-1 macrophages in a dose-dependent manner, suggesting that RA increases cholesterol efflux, resulting in a decrease in foam cell formation.

A

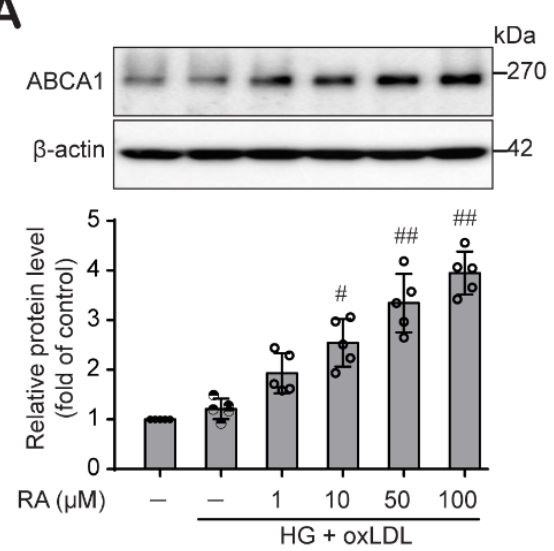

C

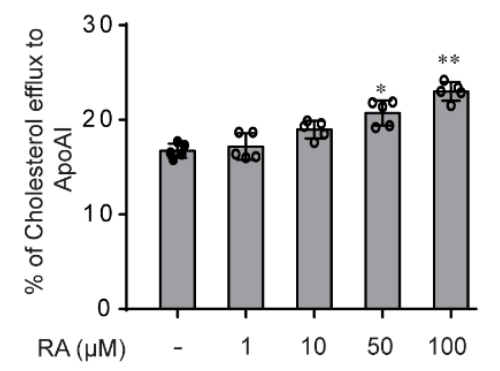

B
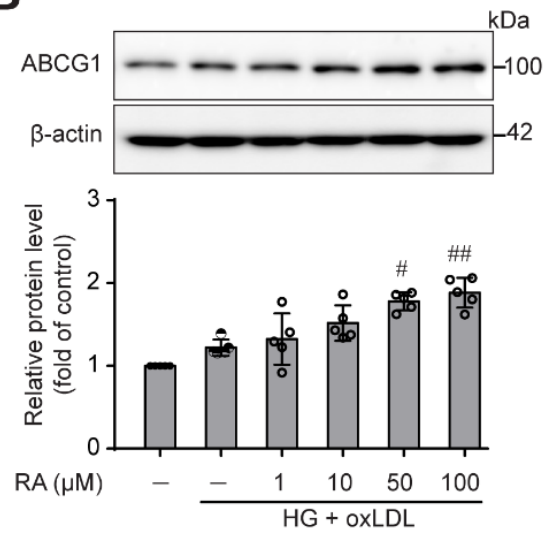

D

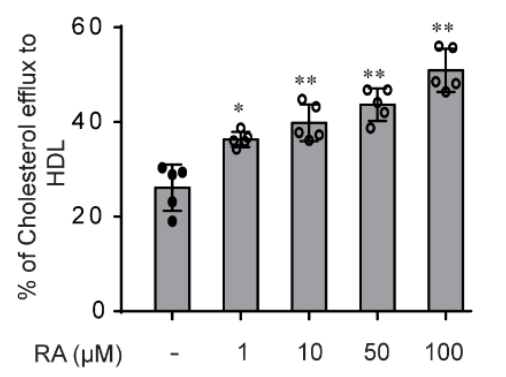

Figure 2. RA enhanced ABCA1 and ABCG1 protein levels and promoted cholesterol efflux in THP-1 macrophages. THP-1 macrophages cultured under HG conditions ( $25 \mathrm{mM})$ for $48 \mathrm{~h}$ were stimulated with oxLDL $(100 \mu \mathrm{g} / \mathrm{mL})$ for an additional $24 \mathrm{~h}$ in the presence or absence of RA (1, 10, 50 and $100 \mu \mathrm{M})$. Cell lysates were collected to determine ABCA1 (A) and ABCG1 (B) protein levels by western blot analysis. Band densities were quantified, and relative protein levels are presented as the mean \pm SD of five independent experiments. (C,D) THP-1 macrophages were labeled with cholesterol and equilibrated for $24 \mathrm{~h}$ in the presence or absence of RA (1, 10, 50 and $100 \mu \mathrm{M})$. Cholesterol efflux was evaluated in THP-1 macrophages after $6 \mathrm{~h}$ of incubation with ApoA1 (C) or HDL (D) as described in the Methods section. The data are presented as the mean $\pm \mathrm{SD}$ of five independent experiments. ${ }^{*} p<0.05,{ }^{* *} p<0.01$ compared to the control; ${ }^{*} p<0.05,{ }^{\# \#} p<0.01$ compared to the HG + oxLDL group.

\subsection{RA Mediated ABCA1 and ABCG1 Expression through the Activation STAT3 Signaling in THP-1 Macrophages}

Next, we explored the mechanisms by which RA induces ABCA1 and ABCG1 expression. Previous studies have shown that JAK2/STAT3 signaling is involved in the modulation of ABCA1 and ABCG1 expression [25,31]. Thus, we investigated whether 
the STAT3 pathway is also involved in RA-mediated ABCA1 and ABCG1 expression. Pretreatment with AG-490 (a specific JAK2/STAT3 inhibitor) significantly abrogated the RA-mediated increase in ABCA1 (Figure 3A) and ABCG1 (Figure 3B) expression. Then, we confirmed that treatment with RA activated STAT3 in a time-dependent manner, with the maximum level observed $4 \mathrm{~h}$ after RA treatment (Figure 3C), which was also inhibited in the presence of AG-490 (Figure 3D). These results suggest that RA induced ABCA1 and ABCG1 protein expression in THP-1 macrophages by activating the JAK2/STAT3 pathway.
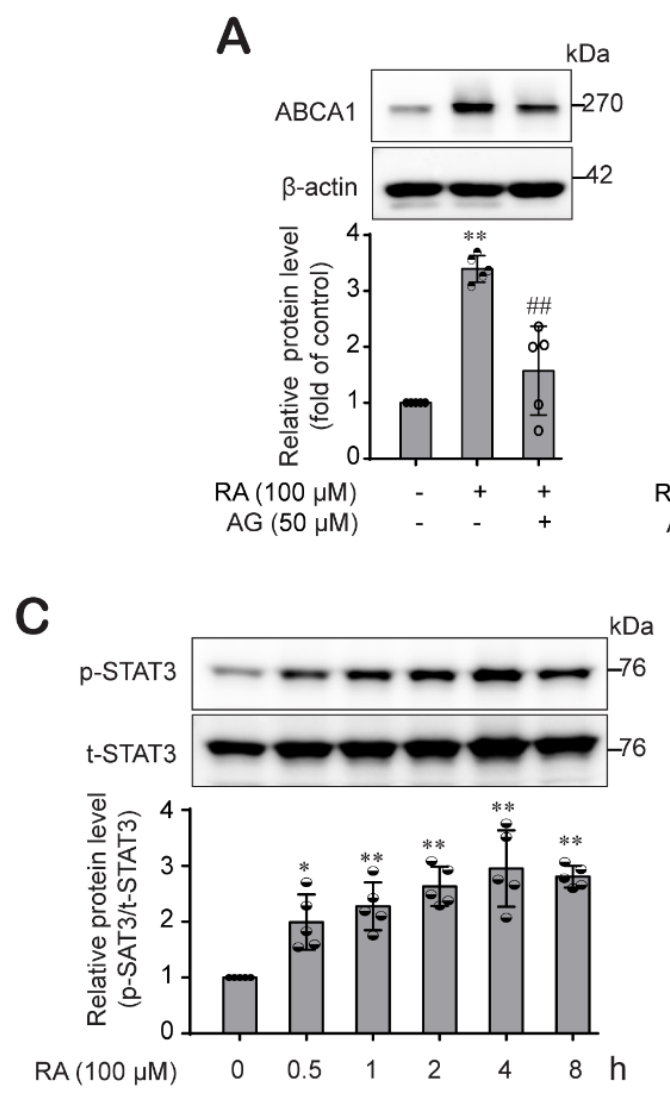

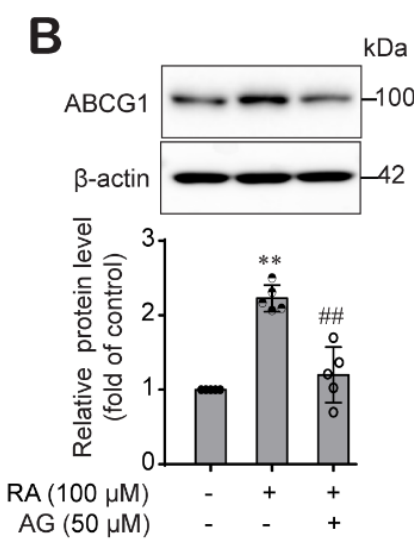

D

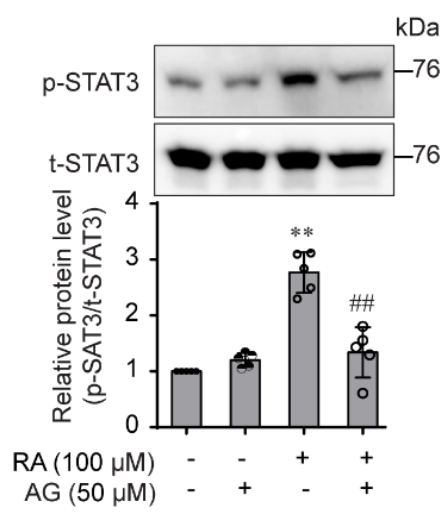

Figure 3. RA increased ABCA1 and ABCG1 protein expression through the JAK/STAT3 signaling pathway in THP-1 macrophages. (A,B) THP-1 macrophages were pretreated with AG490 (a JAK2 inhibitor, $50 \mu \mathrm{M})$ for $1 \mathrm{~h}$ and then treated with RA (100 $\mu \mathrm{M})$ for $24 \mathrm{~h}$. ABCA1 (A) and ABCG1 (B) protein levels were analyzed by western blot analysis. Band densities were quantified, and relative protein levels are presented as the mean \pm SD of five independent experiments. (C) THP-1 macrophages were treated with RA $(100 \mu \mathrm{M})$ for various time durations, after which phospho-STAT3 protein levels were determined by western blotting. (D) Cells were pretreated with AG490 (50 $\mu \mathrm{M})$ for $1 \mathrm{~h}$ and then treated with RA $(100 \mu \mathrm{M})$ for $4 \mathrm{~h}$. The phospho-STAT3 protein levels were determined by western blotting. The data are presented as the mean $\pm \mathrm{SD}$ of five independent experiments. ${ }^{*} p<0.05$, ** $p<0.01$ compared to the control; ${ }^{\# \#} p<0.01$ compared to the RA-treated group.

2.4. $R A$ Induced $A B C A 1$ and $A B C G 1$ Expression through Differential Regulation of the MAPK Pathways in THP-1 Macrophages

In addition to our assessment of the JAK2/STAT3 pathway, we determined the involvement of MAPKs in the RA-mediated increase in ABCA1 and ABCG1 expression in THP-1 macrophages. We pretreated cells with a p38 inhibitor (SB203580), a JNK inhibitor (SP600125) and an ERK inhibitor (PD98059) for $1 \mathrm{~h}$ and then treated them with RA for $24 \mathrm{~h}$. The RA-mediated increase in ABCA1 protein expression was decreased by the $\mathrm{p} 38$ and JNK inhibitors but not by the ERK1/2 inhibitor. However, the RA-induced increase in ABCG1 protein levels was decreased by all inhibitors: the p38, JNK and ERK inhibitors (Figure 4A). 
Furthermore, we assessed whether RA activates the MAPK and PKC signaling pathways. We treated THP-1 macrophages with RA and harvested them after $0.5,1,2,4$ and $8 \mathrm{~h}$ to determine the levels of phospho-ERK1/2, phospho-p38 and phospho-JNK. As shown in Figure 4B-D, RA significantly increased the phosphorylation of ERK1/2 (Figure 4B), p38 (Figure 4C) and JNK (Figure 4D) beginning at 30 min until $8 \mathrm{~h}$.
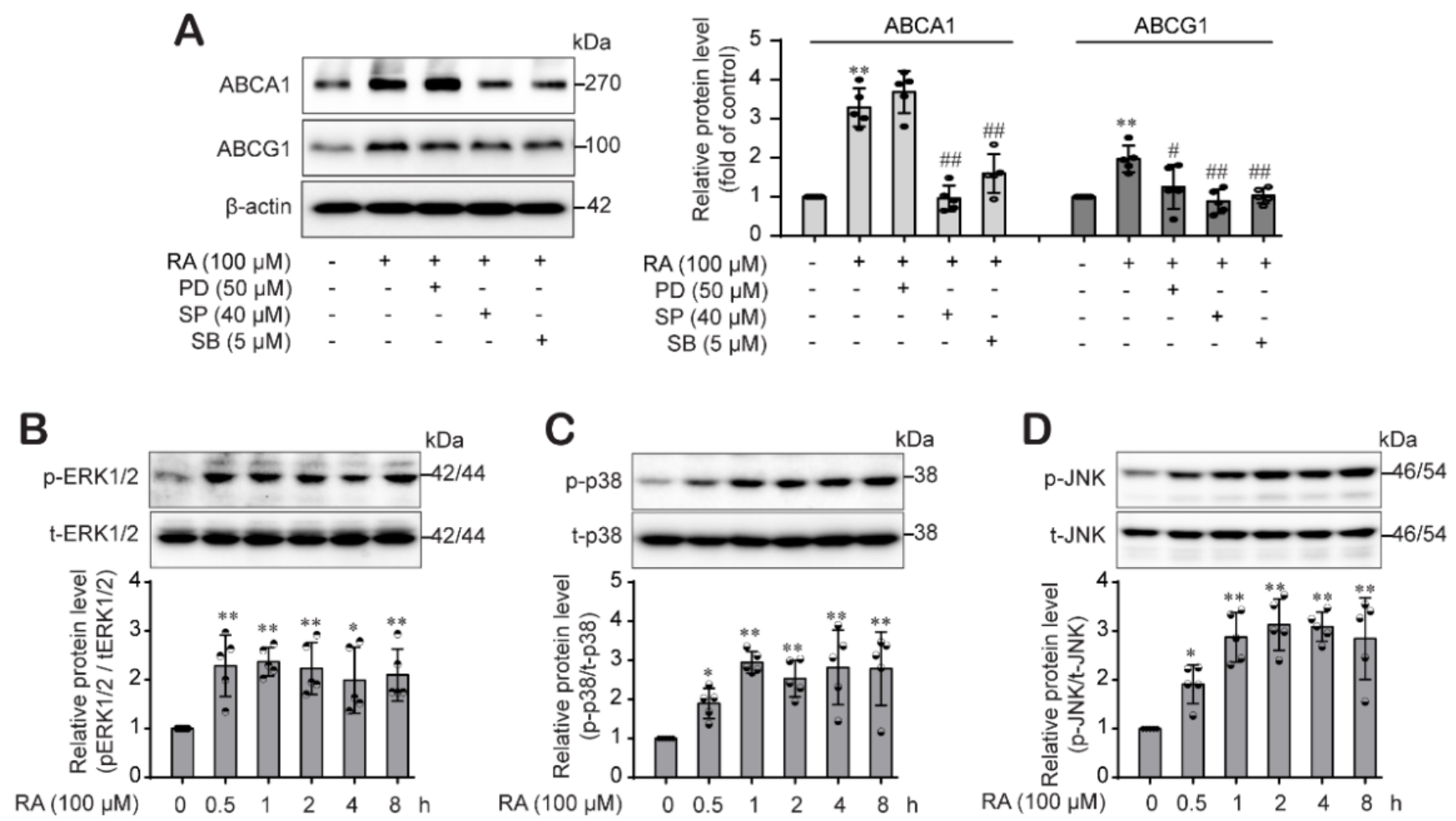

Figure 4. RA differentially regulates ABCA1 and ABCG1 protein expression through the MAPK signaling pathway. (A) THP-1 macrophages were pretreated with the MAPK inhibitors PD98059 (an ERK inhibitor, $50 \mu \mathrm{M}$ ), SB203580 (a p38 inhibitor, $40 \mu \mathrm{M}$ ) and SP600125 (a JNK inhibitor, $5 \mu \mathrm{M}$ ) (A) for $1 \mathrm{~h}$. Then, the cells were treated with RA (100 $\mu \mathrm{M})$ for $24 \mathrm{~h}$, and ABCA1 and ABCG1 protein expression levels were analyzed by western blot analysis. (B-D) THP-1 macrophages were treated with RA $(100 \mu \mathrm{M})$ for various durations $(0.5,1,2,4$ and $8 \mathrm{~h})$, after which phospho-ERK1/2 (B), phospho-p38 (C) and phosphor-JNK (D) protein levels were determined by western blotting. Band densities were quantified and normalized for the loading controls $\beta$-actin or total ERK1/2, total p38 and total JNK. Relative protein levels are presented as the mean \pm SD $(n=5) .{ }^{*} p<0.05,{ }^{* *} p<0.01$ compared to the control; ${ }^{\#} p<0.05,{ }^{\# \#} p<0.01$ compared to the RA-treated group.

2.5. RA-Activated PKC Pathway Was Involved in the ABCA1 and ABCG1 Expression through Differential Regulation of 38 and ERK1/2 Pathway

Moreover, we investigated the role of PKC on the RA-mediated induction of ABCA1 and ABCG1 expression. Results showed that induction of ABCA1 and ABCG1 expression by RA was significantly suppressed by GF109203X (5 $\mu \mathrm{M})$, a PKC inhibitor (Figure 5A), and RA effectively activated PKC pathway from 15 min (Figure 5B). RA-mediated PKC phosphorylation at $15 \mathrm{~min}$ was inhibited in the presence of GF109203X (Figure 5C). Interestingly, the activation of PKC seemed to precede the RA-mediated activation of MAPK, so we tested whether activation of the PKC pathway by RA would affect the MAPK pathway in THP-1 macrophages. We found that RA-activated ERK1/2 (Figure 5C) and p38 phosphorylation (Figure 5D) was significantly reduced by pretreatment with GF109203X, a specific PKC inhibitor. However, RA-induced JNK activation was not affected by GF109203X (Figure 5E). These findings suggest that RA differentially regulates ABCA1 and ABCG1 expression levels; in THP-1 macrophages, RA regulated ABCA1 expression through PKC-p38 MAPK 
and ABCG1 expression through PKC-ERK1/2/p38 MAPK. Furthermore, RA-activated JNK pathway was involved in the ABCA1 and ABCG1 regardless of PKC pathway.
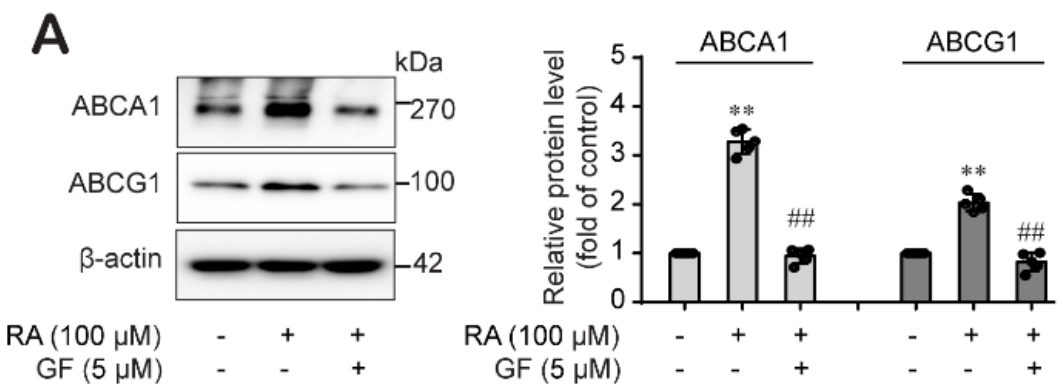
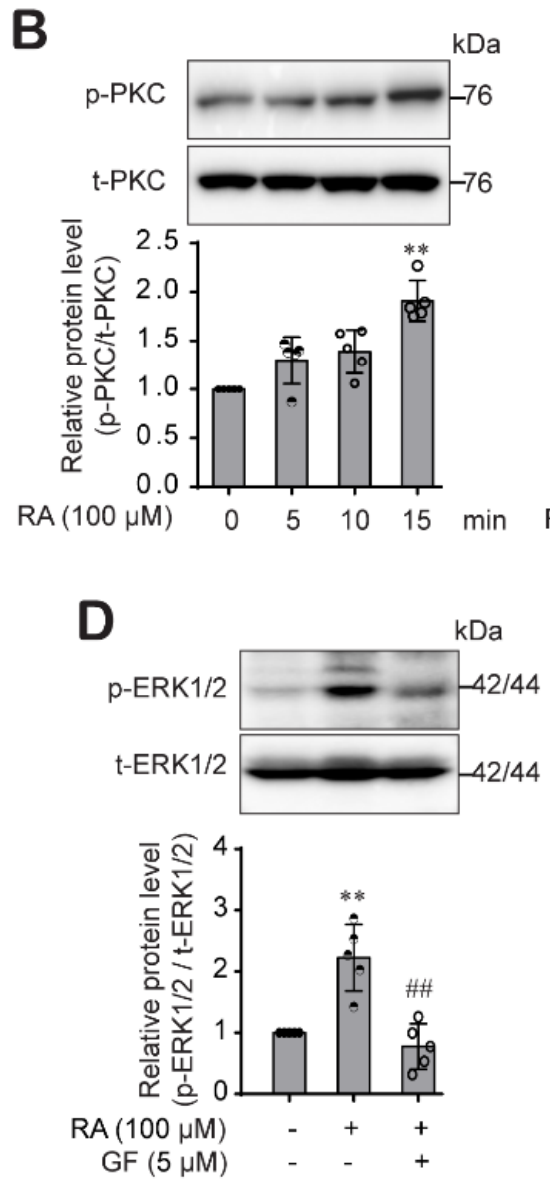

E
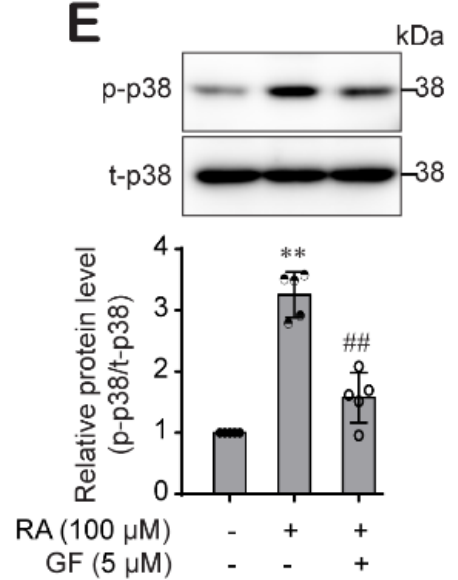

C
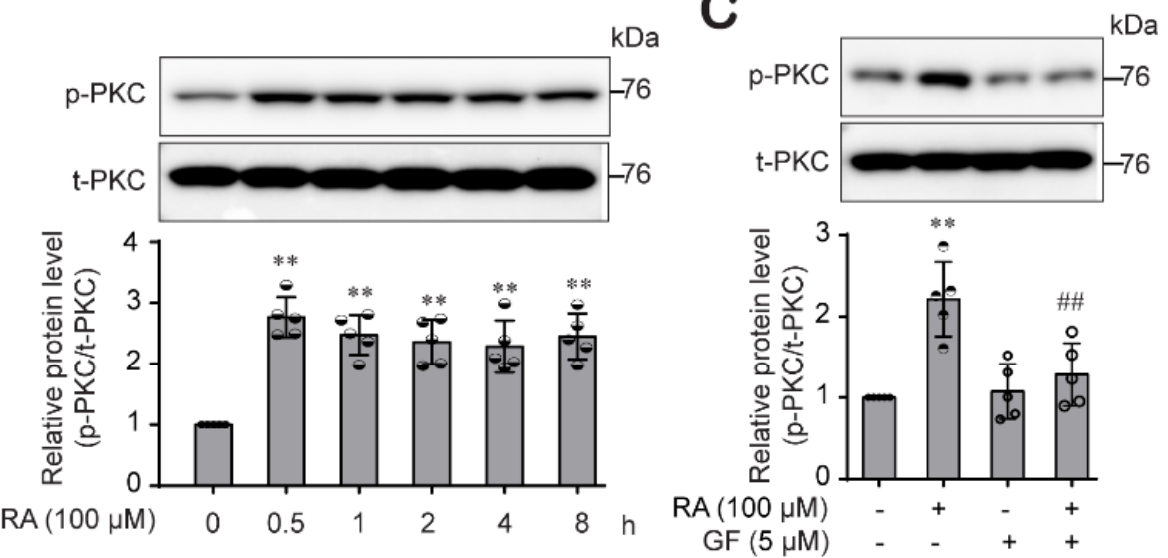

Figure 5. RA-activated PKC pathway was involved in the ABCA1 and ABCG1 expression by differentially regulating p38 and ERK1/2 but not the JNK pathway. (A) THP-1 macrophages were pretreated with GF109203X (a PKC inhibitor, $5 \mu \mathrm{M}$ ) for $30 \mathrm{~min}$ and then treated with RA (100) for $24 \mathrm{~h}$ for the determination of ABCA1 and ABCG1 protein expression by western blot analysis. (B) Cells were treated with RA $(100 \mu \mathrm{M})$ in a time-dependent manner, and then phospho-PKC protein levels were determined by western blotting and normalized for the loading controls total PKC. (C) Cells were pretreated with GF109203X $(5 \mu \mathrm{M})$ for $30 \mathrm{~min}$ and then treated with RA $(100 \mu \mathrm{M})$ for an additional $15 \mathrm{~min}$. Cell lysates were collected and phospho-PKC protein levels were determined by western blotting. (D-F) Cells were pretreated with GF109203X for $30 \mathrm{~min}$ and then treated with RA $(100 \mu \mathrm{M})$ for an additional $30 \mathrm{~min}$ or $1 \mathrm{~h}$ to measure phospho-ERK1/2 protein levels or phospho-p38 and phospho-JNK protein levels, respectively, from the cell lysate by western blotting. Band densities were quantified and normalized, and relative protein levels are presented as the mean $\pm \operatorname{SD}(n=5) .{ }^{* *} p<0.01$ compared to the control; ${ }^{\#} p<0.05,{ }^{\# \#} p<0.01$ compared to the RA-treated group. 


\section{6. $R A$ Stabilized ABCA1 Primarily Rather Than ABCG1 Protein Levels by Impairing Protein Degradation in THP-1 Macrophages}

Lastly, we further examined whether RA increases ABCA1 and ABCG1 protein levels by affecting protein degradation. We treated THP- 1 macrophages with RA for $24 \mathrm{~h}$ to allow $A B C A 1$ and $A B C G 1$ protein synthesis and then blocked de novo protein synthesis by applying $\mathrm{CHX}(140 \mu \mathrm{M})$ for different durations $(10,20,40$ and $180 \mathrm{~min})$. The ABCA1 protein level was significantly reduced from $10 \mathrm{~min}$ and showed less than $50 \%$ the level in the control group at $3 \mathrm{~h}$ after $\mathrm{CHX}$ application (Figure 6A). However, the ABCG1 protein level was not changed at early times and showed the significant decrease at the later time of 180 min after CHX application (Figure 6B). In the presence of RA, the ABCA1 and ABCG1 protein levels was not decreased even in the presence of $\mathrm{CHX}$ (Figure $6 \mathrm{~A}, \mathrm{~B}$ ). In other words, RA treatment significantly restored the ABCA1 and ABCG1 protein levels, mainly $A B C A 1$, even in the presence of CHX. According to reports, ABCA1 and ABCG1 protein degradation involves the proteasome-, lysosome- and calpain-mediated protein degradation pathways [32]. Therefore, we determined the protein degradation pathway through which RA regulates $A B C A 1$ and $A B C G 1$ protein levels using specific inhibitors of these protein degradation pathways: the proteasome inhibitor lactacystin, the lysosome inhibitor chloroquine and the calpain inhibitor calpeptin. Lactacystin, a proteasome inhibitor, and chloroquine, a lysosome inhibitor, augmented ABCA1 and ABCG1 protein levels, as did RA (Figure $6 \mathrm{C}, \mathrm{D}$ ). However, the protein levels of ABCA1 and ABCG1 remained unchanged upon cotreatment with either lactacystin or chloroquine and RA (Figure 6C,D), suggesting that the ability of RA to induce ABCA1 and ABCG1 protein expression is due to inhibition of the lysosome- or proteasome-mediated degradation pathways. In Figure 6E, the calpain inhibitor calpeptin increased $\mathrm{ABCA} 1$ and $\mathrm{ABCG} 1$ protein expression, similar to the effects of RA, and cotreatment with calpeptin and RA did not affect ABCG1 protein level, but interestingly, significantly enhanced $A B C A 1$ protein level. These results suggest that RA stabilized ABCA1 and ABCG1 protein levels through different mechanisms; ABCA1 by impairing proteasome- and lysosome-mediated degradation and ABCG1 by impairing proteasome-, lysosome- and calpain-mediated degradation in THP-1 macrophages.
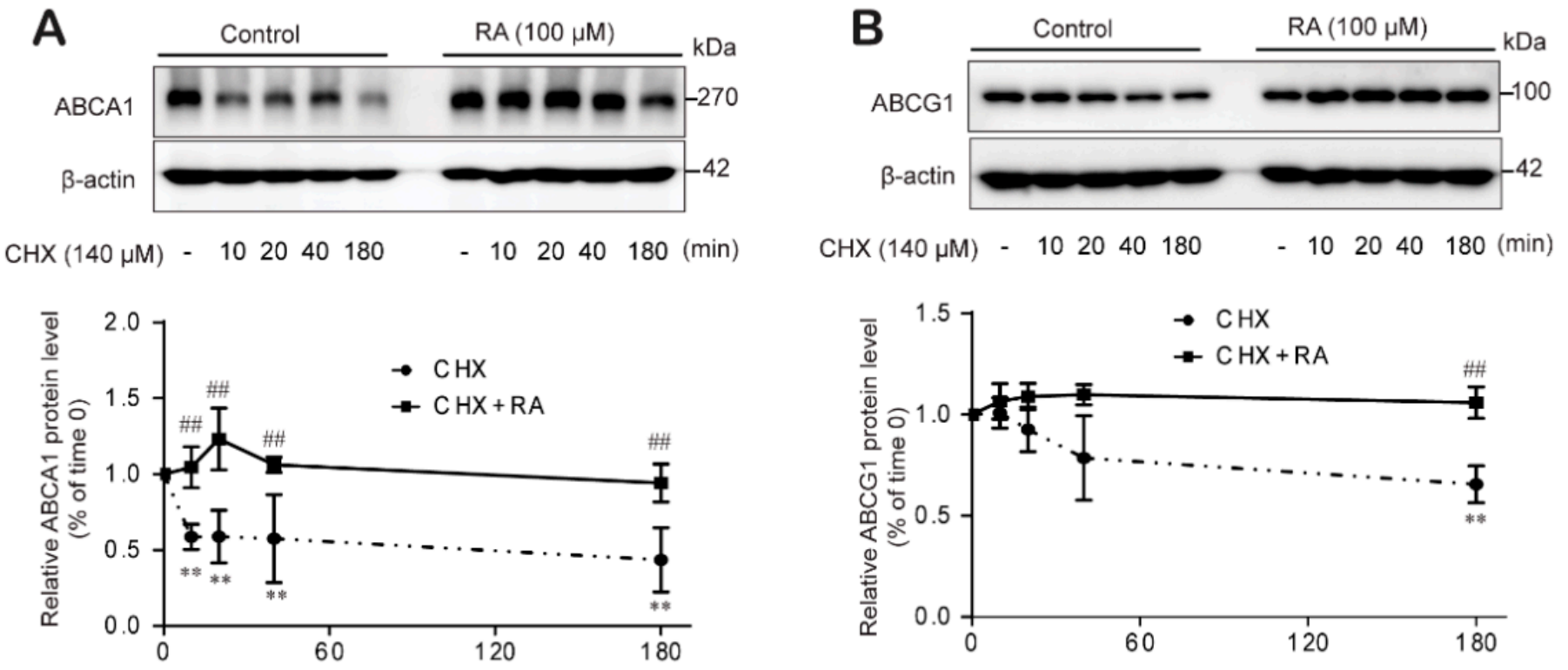

Figure 6. Cont. 

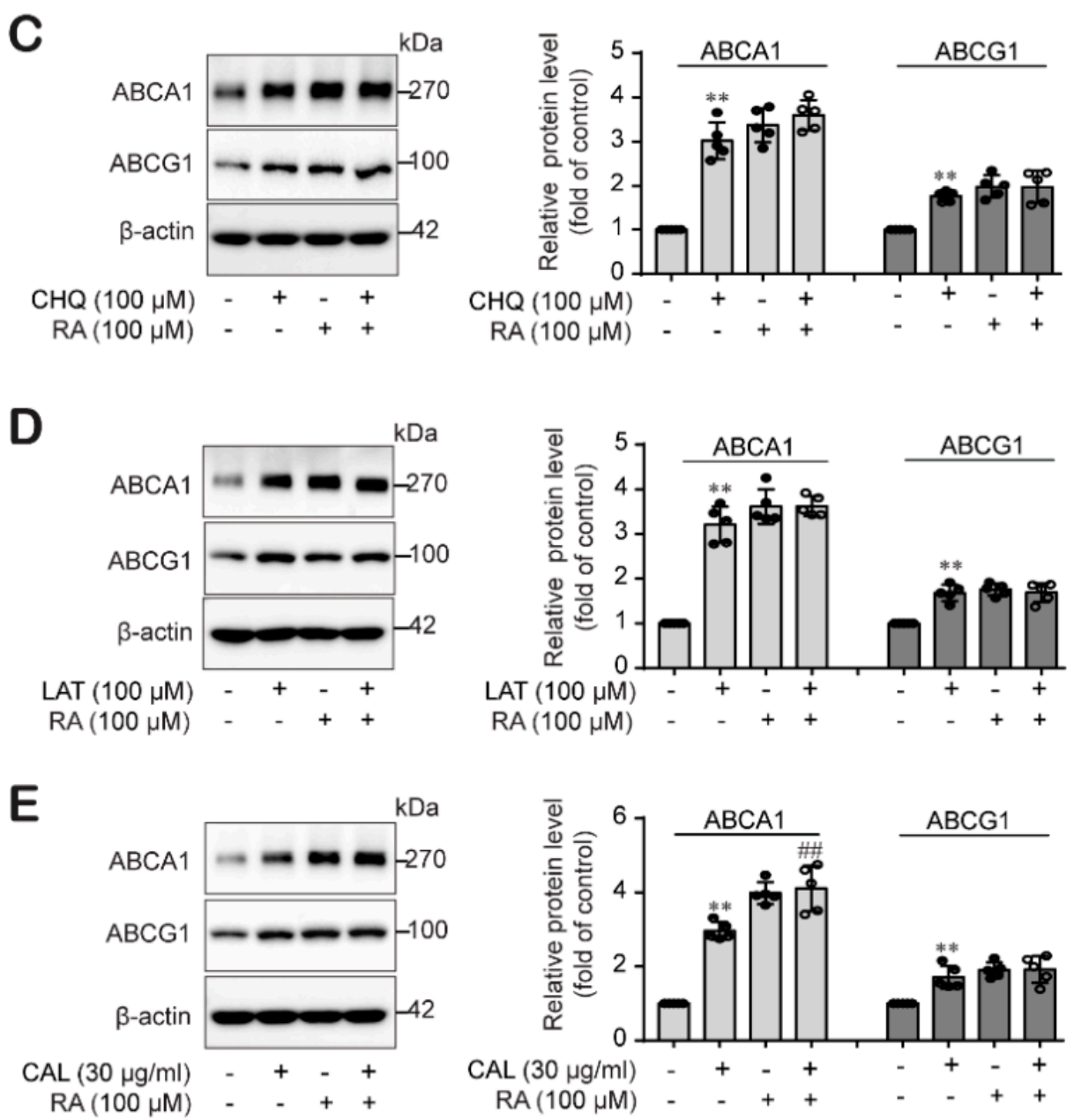

Figure 6. RA stabilizes ABCA1 protein levels by impairing protein degradation. THP-1 macrophages were incubated for $24 \mathrm{~h}$ with or without RA $(100 \mu \mathrm{M})$ and treated with $\mathrm{CHX}(140 \mu \mathrm{M})$ for different durations (0, 10, 20, 40 and $180 \mathrm{~min})$. Cell lysates were collected to analyze ABCA1 (A) and ABCG1 protein levels (B) by western blot analysis. Band densities were quantified, and relative protein levels are presented as the mean \pm SD of five independent experiments. Significance is indicated by ** $p<0.01$ compared with the control; ${ }^{\# \#} p<0.01$ compared to the CHK-treated group. (C-E) Cells were treated with or without RA at $100 \mu \mathrm{M}$ for $24 \mathrm{~h}$ and incubated for another $3 \mathrm{~h}$ with the lysosomal inhibitor chloroquine $(\mathrm{CHQ}, 100 \mu \mathrm{M})(\mathrm{C})$, the proteasome inhibitor lactacystin (LAT, $10 \mu \mathrm{M})(\mathrm{D})$, or the calpain inhibitor calpeptin (CAL, $30 \mu \mathrm{g} / \mathrm{mL})($ E). Cell lysates were collected for ABCA1 and ABCG1 protein analysis using western blot analysis. Band densities were quantified, and relative protein levels are presented as the mean \pm SD of five independent experiments. ${ }^{* *} p<0.01$ compared to the control; ${ }^{\# \#} p<0.01$ compared to the CAL-treated group.

\section{Discussion}

Several studies have reported that hyperglycemia is associated with dyslipidemia and increases the risk of atherosclerotic vascular diseases in diabetes [1,2,33]. Endothelial dysfunction is regarded as the initial step related to atherogenesis under hyperglycemic and dyslipidemic conditions [34]. We previously showed that oxLDL induced inflammasome activation in ECs under HG conditions, but RA effectively inhibited inflammasome activation and the resulting endothelial dysfunction by downregulating the p38-FOXO1-TXNIP pathway [29].

The increased uptake of lipoproteins and reduced cholesterol efflux promote the formation of cholesterol-laden macrophage foam cells, which accelerate the development of atherosclerotic lesions and plaques [35]. Macrophages limit foam cell formation by converting cholesteryl ester into free cholesterol through hydrolyzing modified LDL that has been 
taken up, or through lipolysis and lipophagy of lipid droplets inside the cells. Moreover, cells modulate the cytotoxic effect of free cholesterol by subjecting free cholesterol to RCT or esterifying surplus free cholesterol back to cholesteryl ester [36,37]. Therefore, in this study, we examined the effect of RA on macrophage-mediated lipid homeostasis, lipid uptake and cholesterol efflux. Figure 1C-F shows that RA significantly decreased the oxLDL-mediated increase in intracellular lipid content, total cholesterol and cholesteryl esters under HG conditions in a dose-dependent manner. Interestingly, the cholesteryl ester and total cholesterol contents were significantly reduced by RA at a low dose of $1 \mu \mathrm{M}$ (Figure 1D,F), but a significant decrease in free cholesterol content was observed upon treatment with RA at concentrations beginning at $50 \mu \mathrm{M}$ (Figure 1E). Because the expression of SRs such as CD36 and LOX-1, which mediate the recognition and engulfment of oxLDL, is increased under hyperglycemic and dyslipidemic conditions and mediates the effect of oxLDL [30,38], we further examined whether RA could reduce SR expression and subsequently impair oxLDL-mediated lipid uptake by macrophages under HG conditions. Figure $1 \mathrm{G}$ and $1 \mathrm{H}$ showed that RA significantly decreased expression of the SRs LOX-1 and CD36 induced by oxLDL under HG conditions, suggesting that RA reduces the oxLDL-mediated increase in intracellular lipid content, total cholesterol and cholesteryl esters under HG conditions by reducing expression of the SRs LOX-1 and CD36 induced by oxLDL under HG conditions.

An enormous body of evidence has indicated that cholesterol efflux from macrophages is the main process that inhibits atherosclerosis development [22,39]. Cholesterol efflux is achieved through extracellular cholesterol acceptors such as ApoA1 and HDL, which require the activity of membrane transporters such as ABCA1 and ABCG1 [40,41]. We therefore investigated whether RA could promote cholesterol efflux from macrophages by increasing $A B C A 1$ and ABCG1 expression. We found a significant dose-dependent increase in $\mathrm{ABCA} 1$ and $\mathrm{ABCG} 1$ expression (Figure 2A,B) and ApoA1- and HDL-mediated cholesterol efflux upon RA treatment in macrophages (Figure 2C,D). According to reports, ABCG1 directly supplies free cholesterol to mature HDL, whereas ABCA1 preferentially conveys free cholesterol to lipid-poor ApoA1 to form nascent, immature HDL molecules, which are in turn matured by the lecithin-cholesterol acyl transferase enzyme, hence increasing the number of functional HDL molecules [42,43]. Our findings suggest that RA is an efficient modulator of cholesterol efflux to ApoA1- and HDL acceptor.

Next, we explored the mechanism involved in RA-driven ABCA1 and ABCG1 protein induction. Generally, protein levels are the result of a balance between de novo synthesis and degradation. First, we investigated the signaling pathways pertain to RA-induced ABCA1 and ABCG1 upregulation. Our results showed that RA effectively activated the STAT3 pathway, and RA-induced ABCA1 and ABCG1 expression was significantly inhibited by the selective JAK2/STAT3 inhibitor AG490 (Figure 3A,B), suggesting that RA induced ABCA1 and ABCG1 expression through activation of the JAK/STAT3 signaling pathway in THP-1 macrophages, which is consistent with other reports [24,31]. In addition, we investigated the role of MAPKs and PKC pathways in the RA-induced increase in ABCA1 and ABCG1. p38 MAPK upregulates ABCA1 expression in macrophages through sp1- and LXR-binding sites in the ABCA1 promoter region [44], and ERK1/2 pathway activation also increases ABCA1 expression [12]. Moreover, it has been reported that HSP70 downregulates $\mathrm{ABCA} 1$ and $\mathrm{ABCG} 1$ expression through inhibiting JNK and its downstream Elk-1 in macrophages [45]. Similar to these reports, RA activated the ERK1/2, p38, JNK and PKC pathways (Figure 4B-D and Figure $5 \mathrm{~B}$ ). However, interestingly, we found that PKC is an upstream signal of ERK1/2 and p38 but not JNK (Figure 5E) and that ERK1/2 is involved in ABCG1 induction but not ABCG1 induction by RA (Figure 4A), suggesting that RA induced ABCA1 through the activation of PKC-p38 MAPK and induced ABCG1 through the activation of PKC-ERK1/2/p38 MAPKs in THP-1 macrophages, and furthermore the RA-activated JNK pathway was involved in the ABCA1 and ABCG1 regardless of PKC pathway. Several important studies demonstrated that MAPK-mediated activation of downstream transcription factors resulted in the induction of ABCA1 and ABCG1 in 
macrophages. Tanshinone IIA activated ERK/Nrf2/HO-1 signaling pathway to mediate ABCA1 and ABCG1 induction in macrophages [46]. Similarly, p38 MAPK-activated sp1 interacted with $\mathrm{LXR} \alpha$ to activate ABCA1 transcription in macrophages [44]. Moreover, the activation of the JNK signaling pathway stimulated activator protein-1 (AP-1) DNA binding activity to upregulate ABCA1 expression in macrophages [47]. On the other side, some studies reported ABCG1 degradation in response to p38 and JNK2 activation in macrophages $[48,49]$. Nagelin et al. reported that 12/15-lipoxygnease targets ABCG1 for serine phosphorylation and destabilization through p38- and JNK2-dependent pathways in murine macrophage $[48,49]$. We carefully hypothesize that the difference between our results and the previous works may be partly due to the use of different species of cells. Indeed, murine and human cells possess different ABCG1 isoforms, which present distinct post-translational processing. It is reported that ABCG1 (+12) isoform is expressed in human cells but not in mouse cells [50]. Notably, ABCG1 (+12) phosphorylation stabilized ABCG1 protein levels in human cells and facilitated ABCG1-dependent cholesterol efflux to HDL [51,52]. One more possible reason is that different stimuli may cause different outcomes at different time points, even if they come into contact with the same signaling molecule. In our previous study, oxLDL under HG conditions activated p38 phosphorylation, which was involved in the inflammasome activation [29], but oxLDL stimulation under HG conditions didn't induce ABCA1 and ABCG1 expression in this study. However, RA activated p38 phosphorylation and significantly induced ABCA1 and ABCG1 expression through p38 pathway in this study. Thus, further investigation to elucidate the role of p38 and JNK pathways in human ABCG1 protein degradation is needed. In fact, STAT3 is activated by phosphorylation at both Tyr705 and Ser727 residues. STAT3Tyr705 phosphorylation is mediated by a wide variety of growth factors including IL-6. In response to IL-6, STAT3 is transiently associated with gp130 and subsequently phosphorylated by JAKs on Tyr705 of STAT3 [53]. In addition, STAT3 is a substrate for several protein kinases [54] including ERK1/2 MAPK [55], and PKC directly or indirectly phosphorylates STAT3Ser727 via association with other protein kinase (Raf1, MAPK/ERK1/2 (MEK1/2), ERK1/2, p38MAPK). In our study, we determined the STAT3Tyr705 phosphorylation by RA, so our results in this study do not suggest the role of PKC or other associated protein kinases in the RA-mediated STAT3 phosphorylation.

In addition, we investigated whether RA hampers the rate of ABCA1 or ABCG1 degradation. Upon RA treatment, ABCA1 and ABCG1 protein levels were sustained even in the presence of $\mathrm{CHX}$, rather increased compared to control levels. Interestingly, $\mathrm{CHX}$ mediated protein degradation and the recovery of RA was more prominent in the ABCA1 protein (Figure 6). These results suggest that RA increased the ABCA1 and ABCG1 protein levels, mainly ABCA1, by interfering with protein degradation.

Taken together, these findings suggest for the first time that RA reduces atherosclerotic foam cells and enhances cholesterol efflux from macrophages under HG conditions by inducing the transporters $\mathrm{ABCA} 1$ and $\mathrm{ABCG} 1$, and RA differentially regulates $\mathrm{ABCA}$ and ABCG1 (Figure 7). RA regulates ABCA1 and ABCG1 expression levels through activation of the JAK2/STAT-3 pathway. RA-activated PKC and MAPKs are differentially involved in the effect of RA on ABCA1 and ABCG1; RA induces ABCA1 through PKC-p38 MAPK and induces ABCG1 through PKC-ERK1/2/p38 MAPK in macrophages. Atherogenesis is a complex process that progresses from the development of fatty streaks to the formation of thrombus within the intima. Lipids uptake by macrophages and foam cells formation and subsequent fatty streak formation occurs at early stage of atherogenesis [56]. Moreover, defective cholesterol efflux from macrophages leads to free cholesterol-induced cytotoxicity and may promote macrophage death in advanced lesions [57]. Given that RA modulates macrophage foam cells' formation and increases cholesterol efflux, RA would be beneficial at the early stage of atherogenesis. Further clinical studies are needed. 


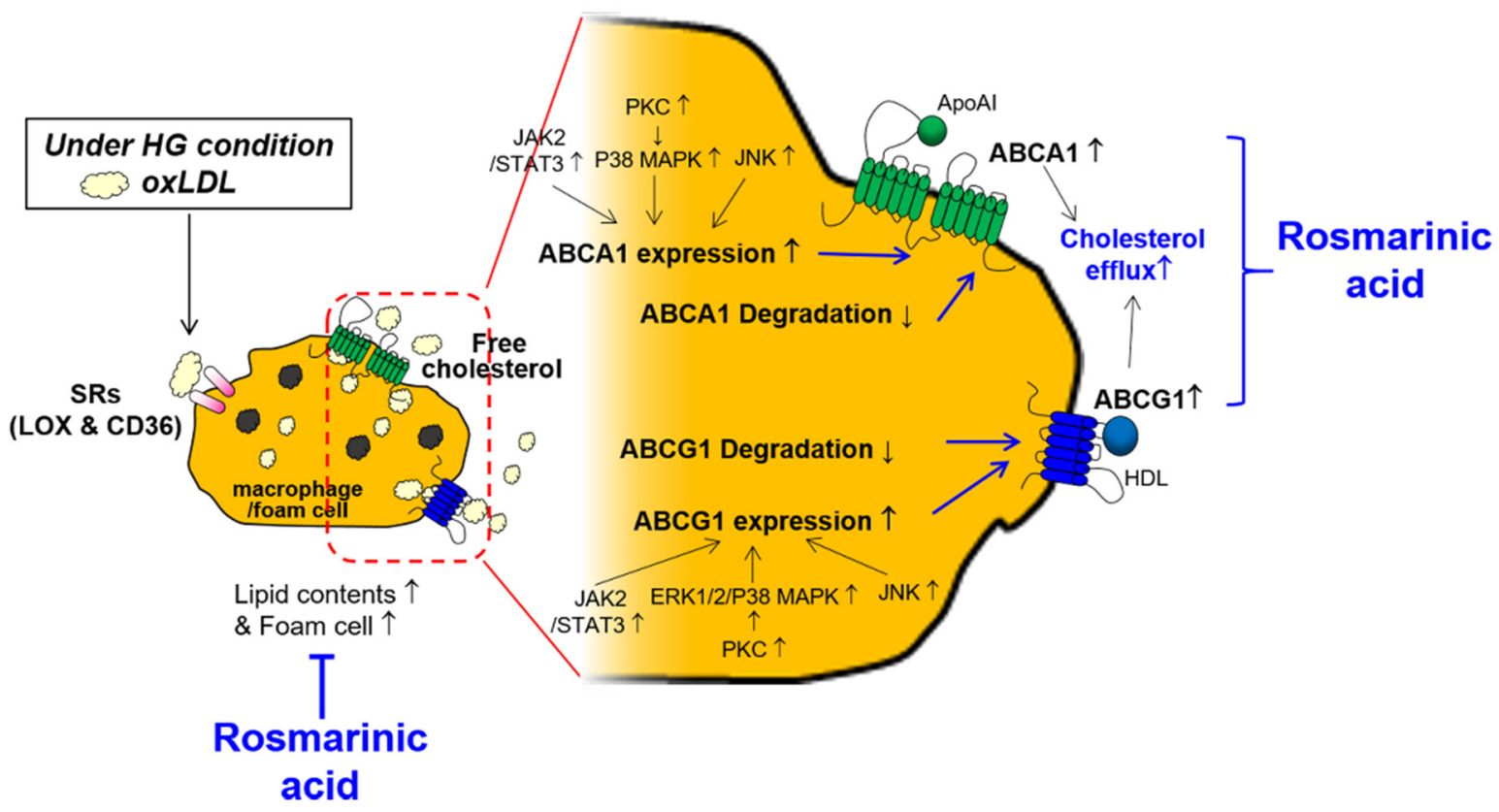

Figure 7. Schematic of the mechanisms by which RA reduces cellular lipid contents and increases cholesterol efflux by macrophages. Rosmarinic acid inhibits foam cells formation by decreasing lipid contents in macrophages and induces cholesterol efflux via upregulating ABC transporters. $\uparrow$; increase, $\downarrow$; decrease, T; inhibit.

\section{Materials and Methods}

\subsection{Materials}

Rosmarinic acid (RA; R4033) was purchased from Sigma-Aldrich (St. Louis, MO, USA). RPMI-1640 medium, DMEM (low glucose, \#SH30021.01; high glucose, \#SH30243.01), fetal bovine serum (FBS), a 100X penicillin-streptomycin solution and 0.05\% trypsin-EDTA were purchased from HyClone Laboratories (Logan, UT, USA). Phorbol 12-myristate 13-acetate (PMA), human low-density lipoprotein (LDL; \#437644), human high-density lipoprotein (HDL; \#LP3) and human ApoA1 (\#178452) were provided by Merck Millipore (Burling, MA, USA). Antibodies against LOX-1 (ab60178), CD36 (ab133625), ABCA1 (ab18180) and ABCG1 (ab52617) were purchased from Abcam (Cambridge, UK). Antibodies against phospho-JNK (\#9251)/JNK (\#9252), phospho-p38 (\#9211), phospho-PKC (\#9375S) and phospho-STAT3 (\#9145)/STAT3 (\#4904) were purchased from Cell Signaling Technology (Beverly, MA, USA). Antibodies against p38 (sc-535), PKC (sc-10800) and phospho-ERK (sc-7383)/ERK (sc-94) were obtained from Santa Cruz Biotechnology (Dallas, TX, USA). Enhanced chemiluminescence (ECL) western blotting detection reagent was obtained from Bio-Rad (Hercules, CA, USA). Lactacystin was procured from Cayman Chemical (Ann Arbor, MI, USA). BCECF was obtained from Boehringer (Mannheim, Germany). PD98059, SP600125, AG490, Oil Red O (ORO), chloroquine diphosphate, calpeptin and an antibody against $\beta$-actin (\#a2066) were purchased from Sigma-Aldrich (St. Louis, MO, USA). SB203580 and GF109203X were obtained from Tocris (Bristol, UK). All other reagents including cycloheximide (CHX; \#C4859) were obtained from Sigma-Aldrich.

\subsection{Preparation of Oxidized Low-Density Lipoprotein (oxLDL) and Cell Treatment}

oxLDL was prepared as described by Ko et al. [58] In brief, human LDL was dialyzed against phosphate-buffered saline (PBS) for $16 \mathrm{~h}$ at $4{ }^{\circ} \mathrm{C}$ to remove EDTA and then oxidized with $5 \mu \mathrm{M} \mathrm{CuSO}_{4}$ for $16 \mathrm{~h}$ at $37^{\circ} \mathrm{C}$. Then, the reaction was stopped by the addition of $1 \mathrm{mM}$ EDTA and incubated for $24 \mathrm{~h}$ at $4{ }^{\circ} \mathrm{C}$. To treat cells with oxLDL at the concentration of $100 \mu \mathrm{g} / \mathrm{mL}$, we added $50 \mu \mathrm{L}$ of oxLDL stock solution $(2 \mathrm{mg} / \mathrm{mL})$ per $1 \mathrm{~mL}$ of media. 


\subsection{Cell Culture and Treatment}

Human THP-1 monocytes were originally obtained from American Type Culture Collection (Manassas, VA, USA). THP-1 cells were grown in RPMI-1640 medium supplemented with $10 \% \mathrm{FBS}, 100 \mathrm{IU} / \mathrm{mL}$ penicillin and $10 \mu \mathrm{g} / \mathrm{mL}$ streptomycin. Cells were maintained in a humidified incubator at $37{ }^{\circ} \mathrm{C}$ with $95 \%$ air and $5 \% \mathrm{CO}_{2}$. The THP- 1 cells were differentiated into macrophages by stimulation with $150 \mathrm{nM}$ PMA for $24 \mathrm{~h}$. Then, the differentiated cells were changed with low glucose DMEM media containing $1 \mathrm{~g} / \mathrm{L}$ of D-Glucose ( $5 \mathrm{mM} \mathrm{Glu}$ ) and $20 \mathrm{mM}$ mannitol as control or high glucose DMEM media containing $4.5 \mathrm{~g} / \mathrm{L}$ of D-Glucose ( $25 \mathrm{mM} \mathrm{Glu})$ as the HG condition. Cells were used at the fifth through ninth passage for all the experiments. All kinase inhibitors and RA were dissolved in dimethyl sulfoxide (DMSO) to prepare stock solutions. The stock solutions were diluted in culture medium to the working concentration as indicated. The final concentration of DMSO was $\sim 0.1 \%(v / v)$.

\subsection{Cell Viability Assay}

THP-1 macrophage were seeded in black 96-well plates and incubated until they reached confluence. The confluent cells were treated with or without RA $(100 \mu \mathrm{M})$ for the indicated time. After treatment, cell viability was measured by the cell counting kit-8 (CCK-8; Dongin biotech, Seoul, Korea) as described previously [29].

\subsection{ORO Staining}

Differentiated THP-1 macrophages were maintained under HG conditions for $48 \mathrm{~h}$, loaded with oxLDL $(100 \mu \mathrm{g} / \mathrm{mL})$ for $24 \mathrm{~h}$ in the presence or absence of RA as indicated, washed three times with PBS and then fixed with $10 \%$ formalin for $10 \mathrm{~min}$ at room temperature. The fixed cells were washed three times with deionized water, stained with $0.5 \%$ ORO (Sigma-Aldrich) for $10 \mathrm{~min}$ at room temperature and then washed three times with deionized water. Cells were observed under a light microscope (Axiovert 40C), and images were acquired with AxioVision 4.5 software (Carl Zeiss MicroImaging GmbH, Jena, Germany).

\subsection{Intracellular Lipid Measurement}

THP-1 macrophages $\left(1 \times 10^{6}\right)$ cultured under HG conditions and stimulated with oxLDL in the presence or absence of RA as described above were washed three times with ice-cold PBS and harvested in $50 \mu \mathrm{L}$ of chloroform:isopropanol:NP-40 (200 mL, 7:11:0.1). The extract was transferred into a centrifuge tube and spun for $10 \mathrm{~min}$ at $15,000 \times \mathrm{g}$. The organic phase was transferred into a new tube and air-dried at $50{ }^{\circ} \mathrm{C}$ to remove the chloroform. The tube was then dried at $100{ }^{\circ} \mathrm{C}$ for $30 \mathrm{~min}$ to remove trace organic solvent. Total cholesterol and free cholesterol in the dried lipids were quantified using the Total Cholesterol and Cholesteryl Ester Colorimetric/Fluorometric Assay Kit (BioVision, Milpitas, CA, USA) according to the manufacturer's instructions. Cholesteryl ester was obtained by subtracting free cholesterol from total cholesterol. The cholesterol content in the sample was calculated from the following formula: sample cholesterol concentration $(\mathrm{C})=\mathrm{B} / \mathrm{V} \times \mathrm{D}(\mu \mathrm{g} / \mu \mathrm{L})$, where $\mathrm{B}$ is the amount of intracellular cholesterol $(\mu \mathrm{g}), \mathrm{V}$ is the volume of sample added to the reaction well $(\mu \mathrm{L})$ and $\mathrm{D}$ is the sample dilution factor.

\subsection{Cholesterol Efflux Assay}

Macrophage-specific cholesterol efflux capacity was measured using a commercially available Cholesterol Efflux Assay Kit (Abcam, ab196985, Cambridge, MA, USA). Briefly, THP-1-derived macrophages $\left(1 \times 10^{5}\right)$ were labeled with a labeling reagent which includes a fluorescent labelled cholesterol and equilibrated for $24 \mathrm{~h}$ in a humidified incubator at $37^{\circ} \mathrm{C}$ and $5 \% \mathrm{CO}_{2}$. Then, the media was removed, and cells were washed with fresh media and treated with RA $(1,10,50$ and $100 \mu \mathrm{M})$ for $24 \mathrm{~h}$. Cells were added with HDL or ApoA1 cholesterol acceptors and incubated for $6 \mathrm{~h}$ more. Thereafter, the cholesterol contents in 
media and cell lysis were measured and cholesterol efflux to HDL or ApoA1 was calculated as follows:

$$
\% \text { cholesterol efflux }=\frac{\text { fluorescence intensity of medium }}{\text { fluorescence intensity of cell lysate }+ \text { medium }} \times 100
$$

\subsection{Protein Extraction and Western Blotting}

Cells were lysed using RIPA buffer ( $25 \mathrm{mM}$ Tris- $\mathrm{HCl}, \mathrm{pH} 7.4,150 \mathrm{mM} \mathrm{NaCl}, 1 \%$ NP-40, $1 \%$ sodium deoxycholate and $0.1 \%$ SDS, $1 \times$ protease inhibitor cocktail) and centrifuged at $16,000 \times \mathrm{g}$ for $20 \mathrm{~min}$ at $4{ }^{\circ} \mathrm{C}$. Then, the protein concentration was quantified from the supernatant and SDS-polyacrylamide gels electrophoresis and western blot analyses were performed according to previously published procedures [26]. As primary antibodies, anti-LOX-1 (1:1000), anti-CD36 (1:1000), anti-ABCA1 (1:1000), anti-ABCG1 (1:1000), anti-phospho-STAT3 (1:500)/STAT3 (1:1000), anti-phospho-PKC (1:500)/PKC (1:1000), anti-phospho-JNK (1:500)/JNK (1:1000), anti-phospho-p38 (1:500)/p38 (1:1000), anti-phospho-ERK (1:500)/ERK (1:1000) and anti- $\beta$-actin (1:5000) antibodies were used. As a secondary antibody, a horseradish peroxidase-conjugated anti-rabbit, anti-mouse or anti-goat secondary antibody (1:5000) was used. The relative level of each protein was normalized to the level of a loading control, such as $\beta$-actin, STAT3, JNK, p38 or ERK.

\subsection{Data and Statistical Analyses}

Scanning densitometry for western blotting was performed using an Image Master®VDS system (Pharmacia Biotech Inc., San Francisco, CA, USA). One-way ANOVA was used to make statistical comparisons, followed by Tukey's multiple comparisons test. The results were expressed as the means \pm standard deviations (SDs) of at least five independent experiments, and a $p$-value $<0.05$ was considered statistically significant.

\section{Conclusions}

RA might be a potential therapeutic candidate to prevent atherosclerotic cardiovascular disease complications related to diabetes.

Author Contributions: J.-B.N. performed the experiments, analyzed the data, and drafted the initial manuscript. Y.S.K. and H.J. performed experiments and analyzed the data. S.W.P. and S.P.Y. discussed and provided important critical feedback about the data and methodology. H.J.K. designed the study, interpreted the data and revised the manuscript. All authors have read and agreed to the published version of the manuscript.

Funding: This work was supported by Basic Science Research Program through the National Research Foundation of Korea (NRF) funded by the Ministry of Science, ICT and Future Planning (NRF-2015R1A5A2008833).

Institutional Review Board Statement: Not applicable.

Informed Consent Statement: Not applicable.

Data Availability Statement: The data that support the findings of this study are available from the corresponding author upon reasonable request.

Conflicts of Interest: The authors declare no conflict of interest.

\section{References}

1. Katakami, N. Mechanism of development of atherosclerosis and cardiovascular disease in diabetes mellitus. J. Atheroscler. Thromb. 2018, 25, 27-39. [CrossRef]

2. Rajendran, P.; Rengarajan, T.; Thangavel, J.; Yutaka, N.; Dhanapal, S.; Gautam, S.; Ikuo, N. The vascular endothelium and human diseases. Int. J. Biol. Sci. 2013, 9, 1057-1069. [CrossRef]

3. Sitia, S.; Tomasoni, L.; Atzeni, F.; Ambrozio, G.; Cordiano, C.; Catapano, A.; Petricone, S.; Tramontana, F.; Naccarato, P.; Camici, P.; et al. From endothelial dysfunction to atherosclerosis. Autoimmun. Rev. 2010, 9, 830-834. [CrossRef]

4. Tziomalos, K.; Athyros, V.G.; Karagiannis, A.; Mikhailidis, D.P. Endothelial dysfunction in metabolic syndrome: Prevalence, pathogenesis and management. Nutr. Metab. Cardiovasc. Dis. 2010, 20, 140-146. [CrossRef] 
5. Fenyo, I.M.; Gafencu, A.V. The involvement of the monocytes/macrophages in chronic inflammation associated with atherosclerosis. Immunobiology 2013, 218, 1376-1384. [CrossRef]

6. Ramachandran, S.; Vinitha, A.; Kartha, C.C. Cyclophilin A enhances macrophage differentiation and lipid uptake in high glucose conditions: A cellular mechanism for accelerated macro vascular disease in diabetes mellitus. Cardiovasc. Diabetol. 2016, 15, 152. [CrossRef]

7. Chistiakov, D.A.; Bobryshev, Y.V.; Orekhov, A.N. Macrophage-mediated cholesterol handling in atherosclerosis. J. Cell. Mol. Med. 2016, 20, 17-28. [CrossRef]

8. Chistiakov, D.A.; Melnichenko, A.A.; Myasoedova, V.A.; Grechko, A.V.; Orekhov, A.N. Mechanisms of foam cell formation in atherosclerosis. J. Mol. Med. 2017, 95, 1153-1165. [CrossRef] [PubMed]

9. Di Pietro, N.; Formoso, G.; Pandolfi, A. Physiology and pathophysiology of oxLDL uptake by vascular wall cells in atherosclerosis. Vascul. Pharmacol. 2016, 84, 1-7. [CrossRef] [PubMed]

10. Duan, J.; Xiang, D.; Luo, H.; Wang, G.; Ye, Y.; Yu, C.; Li, X. Tetramethylpyrazine suppresses lipid accumulation in macrophages via upregulation of the ATP-binding cassette transporters and downregulation of scavenger receptors. Oncol. Rep. 2017, 38, 2267-2276. [CrossRef] [PubMed]

11. Tashiro, Y.; Sato, K.; Watanabe, T.; Nohtomi, K.; Terasaki, M.; Nagashima, M.; Hirano, T.A. glucagon-like peptide-1 analog liraglutide suppresses macrophage foam cell formation and atherosclerosis. Peptides 2014, 54, 19-26. [CrossRef] [PubMed]

12. Wu, Y.R.; Shi, X.Y.; Ma, C.Y.; Zhang, Y.; Xu, R.X.; Li, J.J. Liraglutide improves lipid metabolism by enhancing cholesterol efflux associated with ABCA1 and ERK1/2 pathway. Cardiovasc. Diabetol. 2019, 18, 146. [CrossRef]

13. Chen, S.J.; Tsui, P.F.; Chuang, Y.P.; Chiang, D.M.L.; Chen, L.W.; Liu, S.T.; Lin, F.Y; Huang, S.M.; Lin, S.H.; Wu, W.L.; et al. Carvedilol ameliorates experimental atherosclerosis by regulating cholesterol efflux and exosome functions. Int. J. Mol. Sci. 2019, 20, 5202. [CrossRef]

14. Wang, X.; Collins, H.L.; Ranalletta, M.; Fuki, I.V.; Billheimer, J.T.; Rothblat, G.H.; Tall, A.R.; Rader, D.J. Macrophage ABCA1 and ABCG1, but not SR-BI, promote macrophage reverse cholesterol transport in vivo. J. Clin. Investig. 2007, 117, $2216-2224$. [CrossRef] [PubMed]

15. Jiang, T.; Ren, K.; Chen, Q.; Li, H.; Yao, R.; Hu, H.; Lv, Y.C.; Zhao, G.J. Leonurine Prevents Atherosclerosis Via Promoting the Expression of ABCA1 and ABCG1 in a PPAR $\gamma /$ Lxr $\alpha$ Signaling Pathway-Dependent Manner. Cell. Physiol. Biochem. 2017, 43, 1703-1717. [CrossRef]

16. Yvan-Charvet, L.; Ranalletta, M.; Wang, N.; Han, S.; Terasaka, N.; Li, R.; Welch, C.; Tall, A.R. Combined deficiency of ABCA1 and ABCG1 promotes foam cell accumulation and accelerates atherosclerosis in mice. J. Clin. Investig. 2007, 117, 3900-3908. [CrossRef] [PubMed]

17. Van Eck, M.; Singaraja, R.R.; Ye, D.; Hildebrand, R.B.; James, E.R.; Hayden, M.R.; Van Berkel, T.J.C. Macrophage ATP-binding cassette transporter A1 overexpression inhibits atherosclerotic lesion progression in low-density lipoprotein receptor knockout mice. Arterioscler. Thromb. Vasc. Biol. 2006, 26, 929-934. [CrossRef]

18. Westerterp, M.; Murphy, A.J.; Wang, M.; Pagler, T.A.; Vengrenyuk, Y.; Kappus, M.S.; Gorman, D.J.; Nagareddy, P.R.; Zhu, Z.; Abramowicz, S.; et al. Deficiency of ATP-binding cassette transporters a1 and g1 in macrophages increases inflammation and accelerates atherosclerosis in mice. Circ. Res. 2013, 112, 1456-1465. [CrossRef]

19. Singaraja, R.R.; Fievet, C.; Castro, G.; James, R.; Hennuyer, N.; Clee, S.M.; Bissada, N.; Choy, J.C.; Fruchart, J.C.; McManus, B.M.; et al. Increased ABCA1 activity protects against atherosclerosis. J. Clin. Investig. 2002, 110, 35-42. [CrossRef]

20. Khera, A.V.; Cuchel, M.; de la Llera-Moya, M.; Rodrigues, A.; Burke, M.F.; Jafri, K.; French, B.C.; Phillips, J.A.; Mucksavage, M.L.; Wilensky, R.L.; et al. Cholesterol Efflux Capacity, High-Density Lipoprotein Function, and Atherosclerosis. N. Engl. J. Med. 2011, 364, 127-135. [CrossRef]

21. Khera, A.V.; Demler, O.V.; Adelman, S.J.; Collins, H.L.; Glynn, R.J.; Ridker, P.M.; Rader, D.J.; Mora, S. Cholesterol Efflux Capacity, High-Density Lipoprotein Particle Number, and Incident Cardiovascular Events: An Analysis from the JUPITER Trial. Circulation 2017, 135, 2494-2504. [CrossRef] [PubMed]

22. Shea, S.; Stein, J.H.; Jorgensen, N.W.; McClelland, R.L.; Tascau, L.; Shrager, S.; Heinecke, J.W.; Yvan-Charvet, L.; Tall, A.R. Cholesterol Mass Efflux Capacity, Incident Cardiovascular Disease, and Progression of Carotid Plaque: The Multi-Ethnic Study of Atherosclerosis. Arterioscler. Thromb. Vasc. Biol. 2019, 39, 89-96. [CrossRef]

23. Ozasa, H.; Ayaori, M.; Iizuka, M.; Terao, Y.; Uto-Kondo, H.; Yakushiji, E.; Takiguchi, S.; Nakaya, K.; Hisada, T.; Uehara, Y.; et al. Pioglitazone enhances cholesterol efflux from macrophages by increasing ABCA1/ABCG1 expressions via $\mathrm{PPAR} \gamma / \mathrm{LXR} \alpha$ pathway: Findings from in vitro and ex vivo studies. Atherosclerosis 2011, 219, 141-150. [CrossRef]

24. Chen, K.; Zhao, Z.; Wang, G.; Zou, J.; Yu, X.; Zhang, D.; Zeng, G.; Tang, C. Interleukin-5 promotes ATP-binding cassette transporter A1 expression through miR-211/JAK2/STAT3 pathways in THP-1-dervied macrophages. Acta Biochim. Biophys. Sin. (Shanghai) 2020, 52, 832-841. [CrossRef] [PubMed]

25. Zhang, Y.; Ge, C.; Wang, L.; Liu, X.; Chen, Y.; Li, M.; Zhang, M. Induction of DKK1 by ox-LDL negatively regulates intracellular lipid accumulation in macrophages. FEBS Lett. 2015, 589, 52-58. [CrossRef]

26. Kim, G.D.; Park, Y.S.; Jin, Y.H.; Park, C.S. Production and applications of rosmarinic acid and structurally related compounds. Appl. Microbiol. Biotechnol. 2015, 99, 2083-2092. [CrossRef] [PubMed] 
27. Karthik, D.; Viswanathan, P.; Anuradha, C.V. Administration of rosmarinic acid reduces cardiopathology and blood pressure through inhibition of p22phox NADPH oxidase in fructose-fed hypertensive rats. J. Cardiovasc. Pharmacol. 2011, 58, 514-521. [CrossRef]

28. Sotnikova, R.; Okruhlicova, L.; Vlkovicova, J.; Navarova, J.; Gajdacova, B.; Pivackova, L.; Fialova, S.; Krenek, P. Rosmarinic acid administration attenuates diabetes-induced vascular dysfunction of the rat aorta. J. Pharm. Pharmacol. 2013, 65, 713-723. [CrossRef]

29. Nyandwi, J.B.; Ko, Y.S.; Jin, H.; Yun, S.P.; Park, S.W.; Kim, H.J. Rosmarinic acid inhibits oxLDL-induced inflammasome activation under high-glucose conditions through downregulating the p38-FOXO1-TXNIP pathway. Biochem. Pharmacol. 2020, $182,114246$. [CrossRef]

30. Li, L.; Sawamura, T.; Renier, G. Glucose Enhances Human Macrophage LOX-1 Expression: Role for LOX-1 in Glucose-Induced Macrophage Foam Cell Formation. Circ. Res. 2004, 94, 892-901. [CrossRef]

31. Fu, H.; Tang, Y.Y.; Ouyang, X.P.; Tang, S.L.; Su, H.; Li, X.; Huang, L.P.; He, M.; Lv, Y.C.; He, P.P.; et al. Interleukin-27 inhibits foam cell formation by promoting macrophage ABCA1 expression through JAK2/STAT3 pathway. Biochem. Biophys. Res. Commun. 2014, 452, 881-887. [CrossRef]

32. Wang, L.; Palme, V.; Rotter, S.; Schilcher, N.; Cukaj, M.; Wang, D.; Ladurner, A.; Heiss, E.H.; Stangl, H.; Dirsch, V.M.; et al. Piperine inhibits ABCA1 degradation and promotes cholesterol efflux from THP-1-derived macrophages. Mol. Nutr. Food Res. 2017, 61, 1-10. [CrossRef]

33. Patel, D.C.; Albrecht, C.; Pavitt, D.; Paul, V.; Pourreyron, C.; Newman, S.P.; Godsland, I.F.; Valabhji, J.; Johnston, D.G. Type 2 diabetes is associated with reduced ATP-binding cassette transporter A1 gene expression, protein and function. PLoS ONE 2011, 6, e22142. [CrossRef] [PubMed]

34. Wan, Z.; Fan, Y.; Liu, X.; Zue, J.; Han, Z.; Zhu, C.; Wang, Z. NLRP3 inflammasome promotes diabetes-induced endothelial inflammation and atherosclerosis. Diabetes Metab. Syndr. Obes. Targets Ther. 2019, 12, 1931-1942. [CrossRef] [PubMed]

35. Yu, X.H.; Fu, Y.C.; Zhang, D.W.; Yin, K.; Tang, C.K. Foam cells in atherosclerosis. Clin. Chim. Acta 2013, 424, 245-252. [CrossRef] [PubMed]

36. Ouimet, M.; Barrett, T.J.; Fisher, E.A. HDL and reverse cholesterol transport: Basic mechanisms and their roles in vascular health and disease. Circ. Res. 2019, 124, 1505-1518. [CrossRef] [PubMed]

37. Jeong, S.J.; Lee, M.N.; Oh, G.T. The Role of Macrophage Lipophagy in Reverse Cholesterol Transport. Endocrinol. Metab. 2017, 32, 41-46. [CrossRef] [PubMed]

38. Liang, C.P.; Han, S.; Okamoto, H.; Carnemolla, R.; Tabas, I.; Accili, D.; Tall, A.R. Increased CD36 protein as a response to defective insulin signaling in macrophages. J. Clin. Investig. 2004, 113, 764-773. [CrossRef]

39. Cavelier, C.; Lorenzi, I.; Rohrer, L.; von Eckardstein, A. Lipid efflux by the ATP-binding cassette transporters ABCA1 and ABCG1. Biochim. Biophys. Acta Mol. Cell Biol. Lipids 2006, 1761, 655-666. [CrossRef]

40. Frambach, S.J.C.M.; de Haas, R.; Smeitink, J.A.M.; Rongen, G.A.; Russel, F.G.M.; Schirris, T.J.J. Brothers in arms: ABCA1-and ABCG1-mediated cholesterol efflux as promising targets in cardiovascular disease treatments. Pharmacol. Rev. 2020, 72, 152-190. [CrossRef]

41. Demina, E.P.; Miroshnikova, V.V.; Schwarzman, A.L. Role of the ABC transporters A1 and G1, key reverse cholesterol transport proteins, in atherosclerosis. Mol. Biol. 2016, 50, 193-199. [CrossRef]

42. Khera, A.V.; Rader, D.J. Future therapeutic directions in reverse cholesterol transport. Curr. Atheroscler. Rep. 2010, $12,73-81$. [CrossRef]

43. Tall, A.R. Cholesterol efflux pathways and other potential mechanisms involved in the athero-protective effect of high density lipoproteins. J. Intern. Med. 2008, 263, 256-273. [CrossRef]

44. Chang, Y.C.; Lee, T.S.; Chiang, A.N. Quercetin enhances ABCA1 expression and cholesterol efflux through a p38-dependent pathway in macrophages. J. Lipid Res. 2012, 53, 1840-1850. [CrossRef] [PubMed]

45. Zhao, Z.W.; Zhang, M.; Chen, L.Y.; Gong, D.; Xia, X.D.; Yu, X.H.; Wang, S.Q.; Ou, X.; Dai, X.Y.; Zheng, X.L.; et al. Heat shock protein 70 accelerates atherosclerosis by downregulating the expression of ABCA1 and ABCG1 through the JNK/Elk-1 pathway. Biochim. Biophys. Acta Mol. Cell Biol. Lipids 2018, 1863, 806-822. [CrossRef]

46. Liu, Z.; Wang, J.; Huang, E.; Gao, S.; Li, H.; Lu, J.; Tian, K.; Little, P.J.; Shen, X.; Xu, S.; et al. Tanshinone IIA suppresses cholesterol accumulation in human macrophages: Role of heme oxygenase-1 Oil Red O staining. J. Lipid Res. 2014, 55, 201-213. [CrossRef] [PubMed]

47. Huwait, E.A.; Singh, N.N.; Michael, D.R.; Davies, T.S.; Moss, J.W.E.; Ramji, D.P. Protein Kinase C Is Involved in the Induction of ATP-Binding Cassette Transporter A1 Expression by Liver X Receptor/Retinoid X Receptor Agonist in Human Macrophages. J. Cell. Biochem. 2015, 116, 2032-2038. [CrossRef] [PubMed]

48. Nagelin, M.H.; Srinivasan, S.; Lee, J.; Nadler, J.L.; Hedrick, C.C. 12/15-Lipoxygenase Activity Increases the Degradation of Macrophage ATP-Binding Cassette Transporter G1. Arterioscler. Thromb. Vasc. Biol. 2008, 28, 1811-1819. [CrossRef]

49. Nagelin, M.H.; Srinivasan, S.; Nadler, J.L.; Hedrick, C.C. Murine 12/15-lipoxygenase regulates ATP-binding cassette transporter G1 protein degradation through p38- and JNK2-dependent pathways. J. Biol. Chem. 2009, 284, 31303-31314. [CrossRef]

50. Gelissen, I.C.; Cartland, S.; Brown, A.J.; Sandoval, C.; Kim, M.; Dinnes, D.L.; Lee, Y.; Hsieh, V.; Gaus, K.; Kritharides, L.; et al. Expression and stability of two isoforms of ABCG1 in human vascular cells. Atherosclerosis 2010, 208, 75-82. [CrossRef] 
51. Watanabe, T.; Kioka, N.; Ueda, K.; Matsuo, M. Phosphorylation by protein kinase C stabilizes ABCG1 and increases cholesterol efflux. J. Biochem. 2019, 166, 309-315. [CrossRef]

52. Gelissen, I.C.; Sharpe, L.J.; Sandoval, C.; Rao, G.; Kockx, M.; Kritharides, L.; Jessup, W.; Brown, A.J. Protein kinase A modulates the activity of a major human isoform of ABCG1. J. Lipid Res. 2012, 53, 2133-2140. [CrossRef] [PubMed]

53. Aziz, M.H.; Manoharan, H.T.; Church, D.R.; Dreckschmidt, N.E.; Zhong, W.; Oberley, T.D.; Wilding, G.; Verma, A.K. Protein kinase Cepsilon interacts with signal transducers and activators of transcription 3 (Stat3), phosphorylates Stat3Ser727, and regulates its constitutive activation in prostate cancer. Cancer Res. 2007, 67, 8828-8838. [CrossRef]

54. Jain, N.; Zhang, T.; Kee, W.H.; Li, W.; Cao, X. Protein kinase C $\delta$ associates with and phosphorylates Stat3 in an interleukin-6dependent manner. J. Biol. Chem. 1999, 274, 24392-24400. [CrossRef]

55. Xuan, Y.T.; Guo, Y.; Zhu, Y.; Wang, O.; Rokosh, G.; Messing, R.O.; Bolli, R. Role of the protein kinase C- - -Raf-1-MEK-1/2p44/42 MAPK signaling cascade in the activation of signal transducers and activators of transcription 1 and 3 and induction of cyclooxygenase-2 after ischemic preconditioning. Circulation 2005, 112, 1971-1978. [CrossRef]

56. Moore, K.J.; Tabas, I. Macrophages in the pathogenesis of atherosclerosis. Cell 2011, 145, 341-355. [CrossRef] [PubMed]

57. Barrett, T.J. Macrophages in Atherosclerosis Regression. Arterioscler. Thromb. Vasc. Biol. 2020, 40, 20-33. [CrossRef] [PubMed]

58. Ko, Y.S.; Jin, H.; Park, S.W.; Kim, H.J. Salvianolic acid B protects against oxLDL-induced endothelial dysfunction under highglucose conditions by downregulating ROCK1-mediated mitophagy and apoptosis. Biochem. Pharmacol. 2020, $174,113815$. [CrossRef] [PubMed] 